\title{
Study of Correlation of Serum Uric Acid Level and Cardiovascular Diseases and Its Severity: An Observational Case-Control Study
}

\author{
Arpit Pareek ${ }^{1}$, Dharam P Bansal ${ }^{2}$, Ram K Jat $^{3}$, Pardeep Agarwal ${ }^{4}$, Puneet Rijhwani ${ }^{5}$, Mukesh Jain ${ }^{6}$, Ambika Tyag $^{7}$
}

\begin{abstract}
Background and aim: The normal level of serum uric acid (SUA) is generally $6.5-7 \mathrm{mg} / \mathrm{dL}$ for males and 6-6.5 mg/dL for females. The prevalence of hypertension and complications has rapidly increased worldwide, leading to significantly increased morbidity and mortality. Serum uric acid is one of the emerging recognized laboratory markers for cardiovascular diseases (CVD) in recent years. Thus, we conducted the present study to assess whether there exists an association of SUA with CVD in hypertensive patients.

Materials and methods: This case-control study was conducted in 75 hypertensive patients with 25 cases having cardiovascular disease and 50 hypertensive control attending the OPD and IPD of the Department of General Medicine, Mahatma Gandhi Medical College, Jaipur.

Results: In this study, mean uric acid in CVD patient was $5.89+1.66 \mathrm{mg} / \mathrm{dL}$ and in controls, it is $4.31+1.07 \mathrm{mg} / \mathrm{dL}$. This difference was a statistically significant ( $p$ value $<0.001$ ) negative correlation between uric acid and ejection fraction. It shows with the increment of uric acid levels ejection fraction decreases proportionately. As the severity of cardiovascular disease increases, uric acid levels also increase.

Conclusion: According to our study, it seems that UA is a real risk factor for the development of CVD. We have shown that serum uric acid levels are negatively associated with ejection fraction. Under these conditions of reduced ejection fraction, serum uric acid is an independent risk factor for CVD, respectively, in individuals with hypertension.

Keywords: Cardiovascular disease, Ejection fraction, Serum uric acid.

Journal of Mahatma Gandhi University of Medical Sciences \& Technology (2021): 10.5005/jp-journals-10057-0157
\end{abstract}

\section{INTRODUCTION}

Uric acid synthesis mainly occurs in the liver, intestines, and the vascular endothelium as an end product of an exogenous pool of purines metabolism, and endogenous pool develops from damaged and dying or dead cells, where uric acid is formed from the degradation of nucleic acids like adenine and guanine. Normal serum levels are generally $6.5-7 \mathrm{mg} / \mathrm{dL}$ for males and 6-6.5 mg/dL for females. The prevalence of hypertension and its associated complications has rapidly increased worldwide, leading to significantly increased morbidity and mortality. ${ }^{1,2}$ The appearance of symptomatic cardiovascular disease in elders is usually an outcome of a long process, atherosclerosis of blood vessels. The initiation of this process has been recognized to be early in life, during adolescence, and even earlier in life. Therefore, initial life habits (e.g., of health, nutrition) and their accompanying measurable blood markers should be taken into account while considering the risk of later adulthood CVD. In these circumstances, serum uric acid level is one of the recognized laboratory markers for CVD in recent years.

Thus, we conducted the present study to assess whether there exist an association of SUA with CVD in hypertensive patients.

\section{Materials and Methods}

This study is conducted in hypertensive patients with cardiovascular disease attending the OPD and IPD of the Department of General Medicine, Mahatma Gandhi Medical College, Jaipur.
${ }^{1-7}$ Department of General Medicine, Mahatma Gandhi Medical College and Hospital, Jaipur, Rajasthan, India

Corresponding Author: Ram K Jat, Department of General Medicine, Mahatma Gandhi Medical College and Hospital, Jaipur, Rajasthan India, Phone: +91 797604067, e-mail: drramkishanjat01@gmail.com

How to cite this article: Pareek A, Bansal DP, Jat RK, et al. Study of Correlation of Serum Uric Acid Level and Cardiovascular Diseases and Its Severity: An Observational Case-Control Study. J Mahatma Gandhi Univ Med Sci Tech 2021;6(1):15-16.

Source of support: Nil

Conflict of interest: None

\section{Inclusion Criteria}

Patients aged 18-65 years with systemic hypertension with or without cardiovascular and renal disease with their informed consent.

\section{Exclusion Criteria}

- Patients who fail to give the consent.

- Age $<18$ years and age $>65$ years.

- Patients with chronic alcoholism, chronic liver diseases, rheumatological disorders, connective tissue disorder, diabetes mellitus.

- Patients on the following drugs: beta-blockers, diuretics.

(0) The Author(s). 2021 Open Access This article is distributed under the terms of the Creative Commons Attribution 4.0 International License (https:// creativecommons.org/licenses/by-nc/4.0/), which permits unrestricted use, distribution, and non-commercial reproduction in any medium, provided you give appropriate credit to the original author(s) and the source, provide a link to the Creative Commons license, and indicate if changes were made. The Creative Commons Public Domain Dedication waiver (http://creativecommons.org/publicdomain/zero/1.0/) applies to the data made available in this article, unless otherwise stated. 


\section{Observation and Results(Fig. 1)}

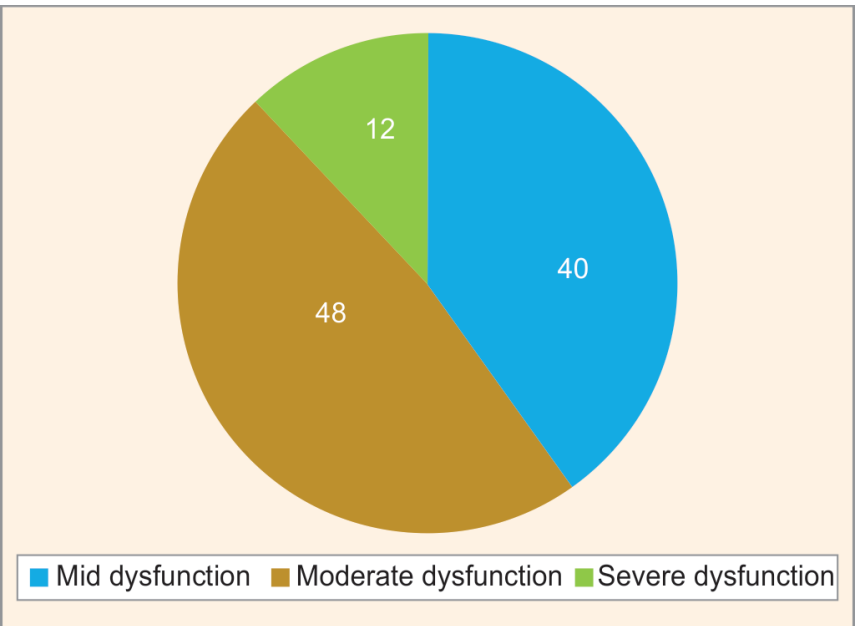

Fig. 1: Distribution of CVD patients on the basis of EF

Table 1: Distribution of CVD patients based on EF

\begin{tabular}{llll}
\hline Groups & LVEF $(\%)$ & CVD (cases) & $\%$ \\
\hline Mild dysfunction & $40-49$ & 10 & 40 \\
Moderate dysfunction & $30-39$ & 12 & 48 \\
Severe dysfunction & $<30$ & 3 & 12 \\
\hline
\end{tabular}

Table 2: Comparison of lipid profile levels between control and CVD cases

\begin{tabular}{lllll}
\hline Parameter & Control & Cases & t value & p value \\
\hline $\begin{array}{l}\text { Cholesterol } \\
\text { (mg/dL) }\end{array}$ & $172.76+41.03$ & $179.76+37.02$ & -0.719 & 0.475 \\
TG $(\mathrm{mg} / \mathrm{dL})$ & $153.94+46.4$ & $224.28+62.12$ & -5.512 & 0.000 \\
HDL $(\mathrm{mg} / \mathrm{dL})$ & $44.56+7.79$ & $41.32+3.91$ & 1.955 & 0.054 \\
LDL $(\mathrm{mg} / \mathrm{dL})$ & $90.43+41.97$ & $93.61+12.44$ & -0.310 & 0.757 \\
VLDL $(\mathrm{mg} / \mathrm{dL})$ & $34.55+8.21$ & $44.86+12.44$ & -4.293 & 0.000 \\
\hline
\end{tabular}

Table 3: Comparison of S. uric acid levels between control and CVD group

\begin{tabular}{lllll}
\hline Parameter & Control & Cases & t value & $p$ value \\
\hline $\begin{array}{l}\text { Uric acid } \\
(\mathrm{mg} / \mathrm{dL})\end{array}$ & $4.31+1.07$ & $5.83+1.66$ & -4.985 & 0.000 \\
\hline
\end{tabular}

Table 4: Correlation of EF with S. uric acid in CVD patients

\begin{tabular}{lll}
\hline Parameter & Correlation coefficient & $p$ value \\
\hline EF vs uric acid & -0.714 & $<0.0001$ \\
\hline
\end{tabular}

\section{Discussion}

In our study, we divided our patient based on 2D echo as Table 1 shows 10 cases (40\%) of mild left ventricular dysfunction, 12 cases (48\%) of moderate dysfunction, and 3 cases (12\%) had severe left ventricular dysfunction.

Table 2 shows mean cholesterol, HDL, and LDL level in CVD cases were $179.76+37.02,41.32+3.91$, and $93.61+12.44 \mathrm{mg} / \mathrm{dL}$, respectively, while in controls it was $172.76+41.03,44.56+7.79$, and $90.43+41.97 \mathrm{mg} / \mathrm{dL}$, respectively. Difference between cases and controls was statistically non-significant ( $p$ value $>0.05$ ). Mean TG and VLDL in cases was $224.28+62.12$ and $44.86+12.44 \mathrm{mg} / \mathrm{dL}$, respectively, and in controls it was $153.94+46.4$ and $34.55+8.21$ $\mathrm{mg} / \mathrm{dL}$, respectively. Difference between cases and controls was statistically significant ( $p$ value $<0.001$ ).

Table 3 shows mean uric acid in CVD patient was $5.89+1.66$ $\mathrm{mg} / \mathrm{dL}$ and in controls it is $4.31+1.07 \mathrm{mg} / \mathrm{dL}$. This difference was statistically significant ( $p$ value $<0.001$ )

Table 4 shows ejection fraction and uric acid had a negative and statistically significant correlation ( $p$ value $<0.001$ ).

In this study, mean uric acid in CVD patient was $5.89+1.66$ $\mathrm{mg} / \mathrm{dL}$ and in controls it is $4.31+1.07 \mathrm{mg} / \mathrm{dL}$. This difference was a statistically significant ( $p$ value $<0.001$ ) negative correlation between uric acid and ejection fraction. It shows with the increment of uric acid levels ejection fraction decreases proportionately. As the severity of cardiovascular disease increase, uric acid levels also increases.

A similar study conducted by Rentzos et al. ${ }^{3}$ in 2019 showed that SUA is an independent risk factor for fatal MI after adjusting for potential confounding variables. Several other studies have also reported a stronger association between SUA and cardiovascular events in women than in men. A study conducted by Wang et al. ${ }^{4}$ in 2010 showed similar results. Alvarez- Lario et al..$^{5}$ in 2013 and Fang et al. ${ }^{6}$ in 2000 showed similar results.

\section{Conclusion}

We conclude that in our study uric acid was significantly high in hypertensive CVD patients in comparison to hypertensive non-CVD controls.

There was a significantly high TG, VLDL level in CVD cases while significantly low HDL in CVD cases in comparison to non-CVD controls.

According to our study, it seems that UA is a real risk factor for the development of CVD. We have shown that serum uric acid levels are negatively associated with ejection fraction. Under these conditions of reduced ejection fraction, serum uric acid is an independent risk factor for CVD, respectively, in individuals with hypertension. The present study gives us an idea that the derangement in the level of serum uric acid may affect the survival of patients with CVD and it is needed to be studied further. Considering all that we can say uric acid levels can be used as a risk factor in correlating the future severity of CVD in hypertensive patients.

\section{References}

1. Fang J, Alderman MH. Serum uric acid and cardiovascular mortality the NHANES I epidemiologic follow-up study, 1971-1992. National Health and Nutrition Examination Survey. JAMA 2000;283(18):24042410.

2. Redon J, Cea-Calvo L, Lozano JV, et al. Kidney function and cardiovascular disease in the hypertensive population: the ERICHTA study. J Hypertens 2006;24(4):663-669. DOI: 10.1097/01. hjh.0000217848.10831.5f.

3. Rentzos M, Nikolaou C, Anagnostouli M, et al. Serum uric acid and multiple sclerosis. Clin Neurol Neurosurg 2006;108(6):527-531.

4. Wang L, Hu W, Wang J, et al. Low serum uric acid levels in patients with multiple sclerosis and neuromyelitis optica: an updated metaanalysis. Mult Scler Relat Disord 2016;9:17-22.

5. Alvarez-Lario B, Macarrón-Vicente J. Is there anything good in uric acid? QJM 2011;104(12):1015-1024.

6. Fang P, Li X, Luo JJ, et al. A double-edged sword: uric acid and neurological disorders. Brain Disord Ther 2013;2(2):109. 